\title{
Efeitos da intervenção fisioterapêutica no equilíbrio de atleta de futsal: estudo de caso
}

Maitê Clarissa Fiabani

Paula Pimentel

Márcia Regina da Silva

CADERNO DE RESUMOS

Fisisenectus. Unochapecó Ano 1 - Edição especial - 2013 p. 124

Maitê Clarissa Fiabani, estudante do $8^{\circ}$ período do curso de Graduação em Fisioterapia da Universidade Comunitária da Região de Chapecó (Unochapecó), maiteclarissa@unochapeco.edu.br

\begin{abstract}
Resumo
Introdução: 0 equilíbrio é um processo dinâmico da postura corporal para prevenir quedas, pela manutenção da projeção do centro de gravidade dentro da área da base de suporte do corpo, que requer ajustes constantes da atividade muscular e do posicionamento articular, baseado nas informações enviadas pela visão, sistema vestibular e sistema proprioceptivo. Objetivo: Avaliar os efeitos da intervenção fisioterapêutica no equilíbrio de um atleta de futsal. Metodologia: Estudo de caso com um atleta praticante de futsal masculino, de 19 anos de idade. Avaliou-se o equilíbrio por meio de Testes de Equilíbrio Estático bipodal, unipodal e equilíbrio tandem olhos abertos (OA) e fechados (OF) em superfície estável (solo) e instável (espuma de média densidade), utilizando como critério o tempo cronometrado que o atleta permaneceu até 1 minuto e o grau de oscilação durante a postura, sendo classificada em leve, moderada e grave. Também foram realizados testes de equilíbrio dinâmico por meio do salto horizontal unipodal reto (SHUR); salto horizontal unipodal cruzado (SHUC) e salto horizontal cronometrado (SHCR). Realizou-se oito intervenções com duração de 60 minutos, uma vez por semana, no Laboratório de Semiologia da Unochapecó, dando ênfase no equilíbrio em solo e superfícies instáveis, utilizando os testes citados acima como tratamento. Resultados: Observou-se melhora no equilíbrio estático e dinâmico de ambos os membros e mais evidente em membro inferior direito (MID). No Teste de Equilíbrio Estático em Superfície Estável (Solo): OF sobre MID: 39s evoluindo para 60s com oscilação moderada; na postura Tanden (apoio em membro dominante) OF, permaneceu 40s na avaliação e 60s na reavaliação, oscilando levemente. Nos Testes de Equilíbrio Estático em Superfície Instável, os resultados obtidos foram: OA sobre MID: 34s, evoluindo para 60s na reavaliação, com oscilação moderada; OF sobre MID: 6s evoluindo para 16s oscilando de forma grave; na postura Tanden OF: 18s na avaliação para 28s na reavaliação, oscilando moderadamente. Nos Testes de Equilíbrio Dinâmico SHUR MID, de 6,2m para 6,5m, não houve diferença para o MIE. SHUC MID de 4,0m para 4,7m e no MIE de 3,7m para 5,0m. SHCR MID de 2,8s para 1,8s e em MIE de $2,2 \mathrm{~s}$ para $1,7 \mathrm{~s}$. Considerações finais: Os resultados do presente estudo demonstraram que o programa de treinamento de equilíbrio melhorou as condições de equilíbrio estático e dinâmico do atleta estudado. São necessários novos estudos com grupos e tempo maior de intervenção correlacionando os efeitos de programas de equilíbrio na prevenção de lesões no esporte.
\end{abstract}

\section{Palavras-chave}

Equilíbrio postural. Propriocepção. Lesões esportivas. 